\title{
SIMULATION OF BULLWHIP EFFECT IN A SUPPLY CHAIN FOR LEAN LEARNING FACTORY PURPOSES
}

\author{
Gjeldum, N.; Crnjac, M. \& Bilic, B. \\ University of Split, Faculty of Electrical Engineering, Mechanical Engineering and Naval Architecture, \\ R. Boskovica 32, 21000 Split, Croatia \\ E-Mail: ngjeldum@ fesb.hr
}

\begin{abstract}
A mission of the Learning Factory (LF) is a development of practice-based engineering curriculum through the simulation of a real factory by specialized equipment. In this paper, supply chain network simulator is developed, as a replacement for the traditional board Beer Game. The board Beer Game could be misused by participants in order to avoid significant bullwhip effect, which occurrence is the Beer Game main aim. The disadvantage of the board Beer Game, that participants have insight in inventory levels and placed orders and thus strategically act upon their knowledge or even activate a sort of decentralized information sharing policy, is avoided. Further considerations prove the mandatory occurrence of bullwhip effect without decentralized information sharing policy on three case studies. Optimal mathematical model for placing orders within a supply chain was defined according to multi-criteria optimization process using spreadsheet simulation. As even optimal model results with the bullwhip effect, newly developed system will always lead to the tremendous bullwhip effect during the learning process.

(Received in December 2016, accepted in May 2017. This paper was with the authors 1 month for 1 revision.)
\end{abstract}

Key Words: Supply Chain Network, Bullwhip Effect, Inventory Level, Beer Game, Learning Factory

\section{INTRODUCTION}

The economy in Croatia is still burdened by previous economic system inherited anomalies and some transitional problems. Obsolete technology and a predominant lack of products and services demanded by developed markets reduced the competitiveness of large public industrial systems. Most of public companies completely disappeared in the privatization process, and those that managed to survive, have undergone numerous recovery programs or have gone into liquidation. Insufficiently educated and unskilled personnel, particularly in the production and the logistics fields, are additionally decreasing competitiveness that is necessary for survival in the global market.

The cooperation between economy and science is rather weak. A basic prerequisite for making a turnaround to a successful economic development in the region is to increase collaboration in the triple-helix model, i.e. between government, university, and industry. In this manner, project Innovative Smart Enterprise intended to develop Croatian model of Innovative Smart Enterprise is financed by Croatian Science Foundation. One of the objectives of the project is to establish a Learning Factory (LF) in one laboratory, i.e. simulation of a real business environment through specialized equipment. The concept of the LF offers a well-suited approach to meet the industries' requirements. The continuous improvement philosophy is facilitated by individual actions and participants' active involvement as a genuine part of the overall learning concept [1]. A developed LF will present learning environment not just for students but for engineers from manufacturing and logistic enterprises [2]. The presented approach enables an effective competency development in Learning Factories by addressing problems of intuitively designed learning systems [3]. In this paper, simulation of bullwhip effect in a supply chain for LF purposes is presented. The new didactic simulator is developed, which is able to present occurrence of the bullwhip effect in the supply chains in every simulation run for learning purposes. 


\section{LITERATURE REVIEW ON INVENTORY MANAGEMENT IN A SUPPLY CHAIN}

A supply chain is, in general, coordinated group of companies with aim of supplying end customer with physical or virtual goods. Supply systems have particular strategic significance because of its impact on overall costs and market share [4]. It could have two, three or more stages, depending on type of product and in some cases physical distances between production plant and end customer. Authors emphasize that the changing business environment, in which supply chain is acting, needs a more effective production process planning and control method that is able to deal with uncertain product demand and forecast from downstream supply chain participant. Similar considerations are presented for remanufacturing supply chain [5]. A fixed cycle joint replenishment policy is proposed, based on the option contract.

Generally, there are two levels of information sharing. The first one is traditional information sharing where the supplier only observes the retailers' orders. The second one is decentralized information sharing policy where supplier has immediate access to the retailers' inventory data [6]. In literature, researches often mention how information sharing between partners in the supply chain is a key for reducing costs of inventory [7]. Distorted information along the supply chain can lead to tremendous inefficiencies like excessive inventory, misguided capacity plans, missed production schedules, poor costumer services and ineffective transportation planning. Because costumer demand is commonly changing over time, participants must forecast its own demand in order to properly define inventory levels. In a supply chain, for a typical final product customer, even when customer sales do not seem to vary much, there is increased variability in the, for example, retailers' orders to the distributor. This situation leads to the bullwhip effect, and the aim of every participant's inventory management is to try to avoid this effect.

The bullwhip effect was firstly described by Forrester [8]. Forrester found that the participant's own policies, sensible and rational from the perspective of the manager's point, led to substantial amplification of perturbations in orders, and instability for the system as a whole. The distortion of demand when moving upstream in a supply chain shows three typical behaviours: oscillation, amplification, and phase-log [9]. Oscillation behaviour refers to the fact that demand is not stable while amplification behaviour means that demand variability increases when one moves upstream in the supply chain. Phase-log behaviour refers to the fact that the order rate trends to peak later as one moves upstream in the supply chain. According to the lean production principles, excessive production and high inventory level are the biggest waste in production process [10]. To solve the problem of distorted information, companies need to first understand what creates the bullwhip effect so they can counteract it [11]. Some results suggest that companies by attacking the institutional and inter-organizational infrastructure and related processes could gain control of the bullwhip effect [12]. Innovative companies in different industries have found that they can control the bullwhip effect and improve their supply chain performance by coordinating information and planning along the supply chain. Demand forecasting is frequently different from the actual production plan [13]. Because forecast errors occur, companies need to have an inventory buffer called safety stock. Some of the main causes for the bullwhip effect are:

- Forecast errors

A forecast error consists of underestimating and overestimating a demand which can lead to a backlog or an overstock. The literature in the forecasting error area indicates that forecast errors can significantly influence the performance of an inventory system [14]. The connection between forecasting and the bullwhip effect arises from inventory control strategies of every participant in a supply chain. This strategy aims to retain inventory level 
between minimum and maximum level defined by min-max inventory policy. Here, whenever the inventory level at a facility is less than a given number, referred as reorder point, the facility raises its inventory level up to a given target level, called the order-up-tolevel [15].

- Lead times of production and delivery

Materials and information delays in a supply chain can be calculated in a manner of lead times. The production lead time is a total amount of time needed for processing, assembly, storage between processes and inbound logistic of the production phase. In the supply chain, delivery lead time consists of processing information, loading and unloading process durations and transportation times. The lead times have a big impact on cost savings and inventory reductions [7]. Misinformation inside of the supply chain increases if the only local information is used to take decisions under uncertainty [16]. If the lead times are random, in the case of customized or personalized production, it increases the possibility for bullwhip effect occurrence.

- Unsettled orders and batch ordering

The upstream participants could saw a distorted and highly variable pattern of orders. It is a result of min-max inventory policies when downstream participants use batch ordering. The period between batch orders are generally not the same, and if several downstream participants are served, inequality of total demands over time period occurs, probably without any recognizable pattern to avail for forecasting. It is very important that companies understand the impact of batch size on the bullwhip in order to make right decisions. It is shown that the bullwhip levels which come from batching can be reduced if the batch size is a multiple of average demand [17].

- Inventory rationing

Generally, every upstream participant of supply chains serves several downstream participants. In some cases, for different reasons, if more downstream participants order higher quantities of products at the same time, an upstream participant could run out of stock and be encouraged to increase its next demand that, if not optimally decided, will trigger the bullwhip effect.

- Inflated orders

The inflated orders are common when participants suspect that a product will be in short supply, and therefore anticipate receiving supply proportional to the amount ordered. When the period of the shortage is over, the participants return to it standard orders, leading to all kind of distortions and variations in demand estimations.

- Price fluctuations

The price fluctuations encourage buying products at lower price and thus overstocking to anticipate price changes. This is accentuated by the prevailing practice in many industries of offering promotions and discounts at certain times or for certain quantities [18]. A possible way to control the bullwhip effect due the price fluctuation is to reduce the frequency as well as the depth of manufacturers' trade promotions [12].

- Products promotions and season discounts

Promoting a product or selling it for discounted price, due to season sales, temporarily leads to a large increase of demands followed by a period of demands that are less than average. The effects of product promotions are similar to those of price fluctuations, except that the period at which those disturbances takes place is chosen by the upstream company, and not by the downstream market. Companies must consider the impact of a price discount on the supply chain and evaluate the success of the marketing activity with the added supply chain costs included [19]. 
- Panic ordering reactions after unmet demands

This situation appears when unexpectedly large demands arise, which causes participants to go out of stock. It induces one or several consecutive significant orders which may lead to overstock. In the same time, due to the increased demand, upstream participants could go out of stock.

- Costumer order reductions or cancellations

Generous order reductions or cancelations introduce disturbances in the demand that, if significant and repetitive, activate instability of inventory level.

These effects can lead to either inefficient production or excessive inventory as the producer needs to fulfil the demand of its predecessor in the supply chain. It is important to use techniques and tools that can control the bullwhip effect [15]. Many researches have tried to find evidence of the bullwhip effect in real life environment [16]. One of the easiest ways to prove the occurrence of bullwhip effect to learners is by using board Beer Game.

In this paper, the newly developed didactical tool for learning factory is presented. It is based on the traditional board Beer Game. The Beer Game is one of many management flight simulators developed at Sloan School of Management at Massachusetts Institute of Technology for these purposes. The game was developed by Sloan's System Dynamics Group in the early 1960s as part of Jay Forrester's research on industrial dynamics. A full analysis of the Beer Game is presented by Sterman [20]. By new didactic tool, some disadvantages of the board Beer Game are voided. The game speed is increased and easiness to administer is achieved by voiding of written reports and manipulation of physical objects that presents beer. Secondly and more importantly, participants cannot enjoy an unwanted transparency of inventory levels and incoming demands. Thus, they cannot strategically act as a team, or even behave according to decentralized information sharing policy. Further considerations in this paper prove the mandatory occurrence of the bullwhip effect if a supply chain acts without decentralized information sharing policy. By modelling of three customer demand case studies, simulation and optimization of order quantities, occurrences of the bullwhip effect were not voided. Nevertheless, the optimal mathematical models for all three case studies are presented, according to participant's preferences. Therefore, one of this paper goals was to prove the necessity of new didactic tool development, in order to achieve the significant bullwhip effect in every game simulation run. It will be achieved by avoiding the decentralized information sharing policy formation among participants.

\section{DEVELOPMENT OF THE DIDACTIC TOOL FOR THE LEARNING FACTORY}

The board Beer Game is played on a board that portrays the production and distribution of beer (Fig. 1). Each team consists of four stages: retailer, wholesaler, distributor, and factory, arranged in a linear distribution chain. Each simulated week, customers purchase from the retailer, who ships items requested out of inventory. The retailer in turn orders from the wholesaler, and so on. The player's objective is to minimize total team costs. Backlog costs are double then inventory holding costs. The game is initialized in equilibrium according to Fig. 1 and it runs with stable customer demands for three weeks. 


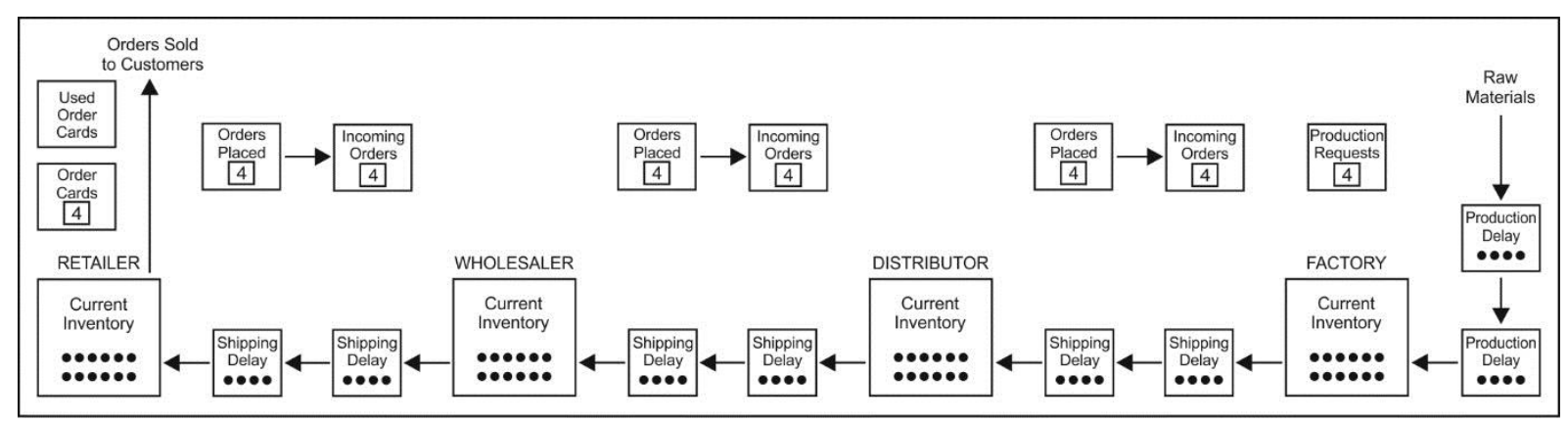

Figure 1: The Beer Game board, showing initial conditions.

Players keep records of their inventory, backlog, and orders placed with their supplier each week on a paper sheet. However, participants are directed not to communicate with one another. Information is supposed to pass only through orders and shipments. Only the retailer discovers customer's demand as the game proceeds. These information limitations imply that the players are unable to coordinate their decisions or jointly plan strategy, even though the objective of each team is to minimize total costs. Participant's job is to forecast demand [21].

To avoid disadvantages of the board Beer Game, the new didactic tool is developed. It is an electronic system consisted of small independently running devices which are connected by communication wires to the master device. Every participant in the game presents one supply chain stage and uses one device with display and keyboard to make decisions and drive own warehouse management. The trainer uses a master device connected to the computer desktop to lead game through simulated periods. Therefore, simulation data can be gathered, processed and presented on the projector during or immediately after simulation, which enables trainer and participants to discuss and make conclusion according to their own simulation results. The layout of devices and participants in the classroom is shown in Fig. 2.

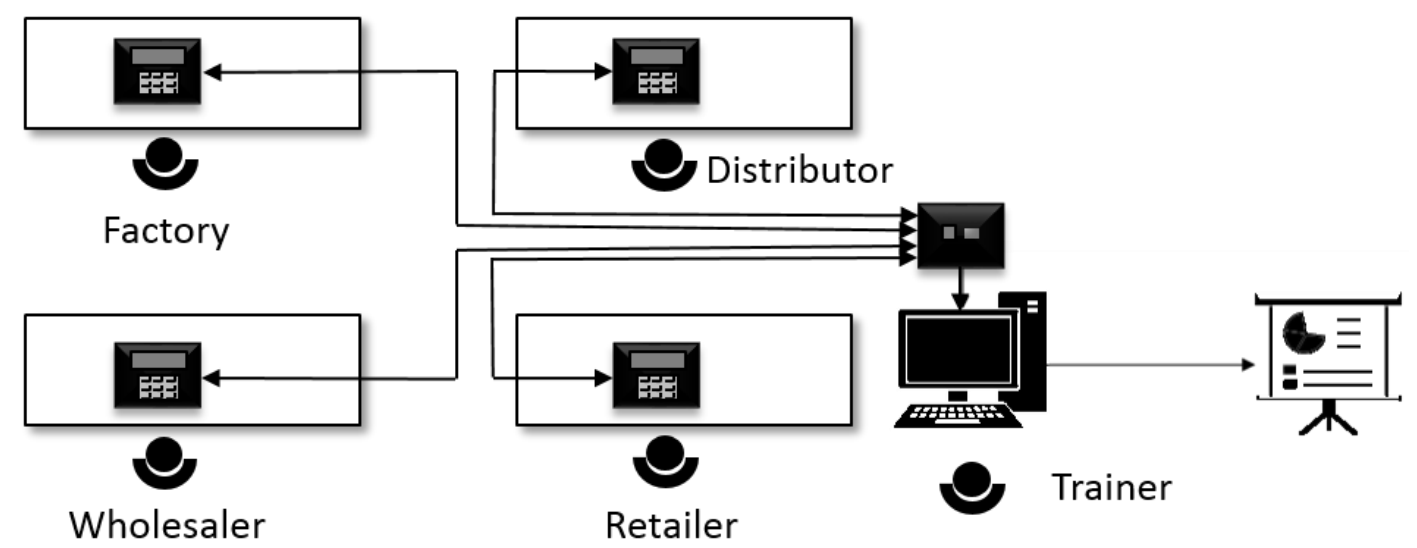

Figure 2: The newly developed system for supply chain simulation.

By proposed set-up, some disadvantages of the traditional version of beer game are voided. There are few main disadvantages of the traditional version with board game: firstly, the board Beer Game is relatively slow and complex to administer. Secondly and more importantly, because physical objects are used to represent inventory on the board, people enjoy an unwanted transparency of inventory levels of other supply chain stages and can thus strategically act upon their knowledge of other participant's stock. Other disadvantages are related to the accuracy of inventory and backlog recording on a paper sheet. Need for subsequent data analysing and representing in form of graphs, require additional trainer effort which is time-consuming.

Using the developed system, participants cannot see other participant's inventory level and order quantities, as they are positioned at four distanced tables. The whole 
communication goes through the system. There are no physical objects and all calculations and recordings on inventory or backlogs are done by the system, which is considerably faster. An additional advantage is ease of changing market demands scenarios and by minor hardware and software changes, different types of serial and divergent Supply Chain Networks (SCN) could be simulated.

During training with the board Beer Game, the fact that participant works as a team and siting close to each other leads to spontaneous activity in improving supply chain performance. Sharing of information to adjust order quantities could lead to total avoidance of the bullwhip effect occurrence. By further considerations in this paper, simulation and optimization of orders quantities along SCM is presented, in order to prove the fact that it is not possible to correctly predict customer demands and act properly upon those to prevent the bullwhip effect.

\section{SIMULATION MODELS AND EXPERIMENTATION RESULTS}

The simulated four-stage supply chain is inspired by the board Beer Game presented in Fig. 1. The spreadsheet simulation is used together with programing of optimization algorithm in Visual Basic for Application tool. The spreadsheet simulation modelling is also used by Buchmeister et al. for simulation of four stage supply chain with the level constraints represented by the overall equipment effectiveness (OEE) [22]. During the spreadsheet forming, several assumptions are taken into account:

- Simulation runtime is 52 weeks or 1 year. The simulation is initialized in equilibrium.

- One week is one period, in which participants can ship orders and set demands to their suppliers.

- Participants are working without decentralized information sharing policy. Placed orders from participants to upstream participants in the supply chain are not visible immediately to those. The demands set by downstream participants have one week delay before revealed to upstream participants.

- Simulated shipment i.e. the delivery lead time between participants is two weeks. Participants have information how many products are in which shipping stage.

- In case that one of the participants cannot fulfil the whole order, it will keep the shortage amount as a backorder to be fulfilled as soon as its inventory level increases.

- Factory has infinite quantities of raw material for production. Similar to other participants, the lead time for shipment of ordered raw material to Factory is two weeks.

\subsection{Single change in demand - case study 1}

The demand used in this case study is scaled model presented by Sterman [20], which is a single increase of demand on 160 items per period after four periods of stable order level with 80 items per period. Increased demand continued to the end of simulated runtime. The stock keeping policy is defined in advance. Total 200 items are supposed to be stored in stock after every period, which presents a level of safety stock. Theoretically, when customer increases demand up to 160 items per period, the Retailer needs to react by demanding 240 items to refill stock for the current period and to provide stock for next period of increased order. That assumption is one of the most important drivers for the bullwhip effect. Upstream the supply chain, order quantities raise according to the same rule. One week later, the Wholesaler receives an order of 240 instead of 80 , so its' order should raise up to 400 to the Distributor and so on. Immediately, in a week of receiving increased orders, the Distributor and the Factory run out of stock with a backlog of 120 and 440 items respectively. The orders of supply chain participants, with an effort to maintain constant safety stock level, are shown in Fig. 3. Due to the stock keeping policy, order delay and shipment delay, a tremendous number 
of 16440 items has to be ordered by the Factory in the $14^{\text {th }}$ week. In Fig. 4 stock levels of supply chain participants, including backlogs, show that the most of participant's warehouses became fulfilled after $18^{\text {th }}$ week with a large number of items. That causes stagnation of ordering and shipping activities.

An isolated impulse in the variability of customer's orders yields the same bullwhip in serial or divergent SCNs [23]. A similar case study is investigated by Buchmeister et al. [24] with a difference that used change in demand was reducing order quantity for only $5 \%$. Results of spreadsheet simulation showed the fluctuation of $61 \%$ in the third stage, and even stopping of the production in the fourth stage. Participants will rarely use this stock keeping policy for defining demand quantity. They will make effort to smoothen their variation in orders and warehouse level as much as possible. If defined incorrectly, their order quantities can lead to stock out, or to very high inventory levels. On the other side, the order quantities influence on transportation costs.

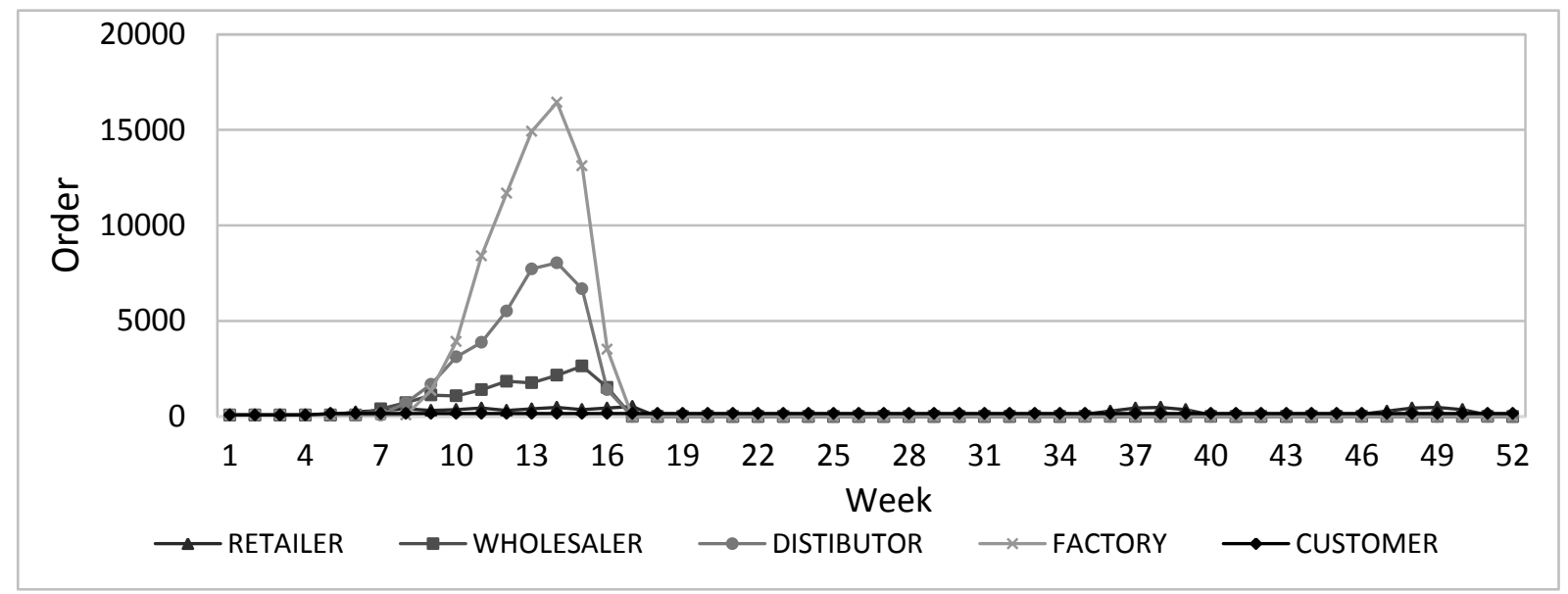

Figure 3: Customer demand and order quantities of supply chain participants for case study 1.

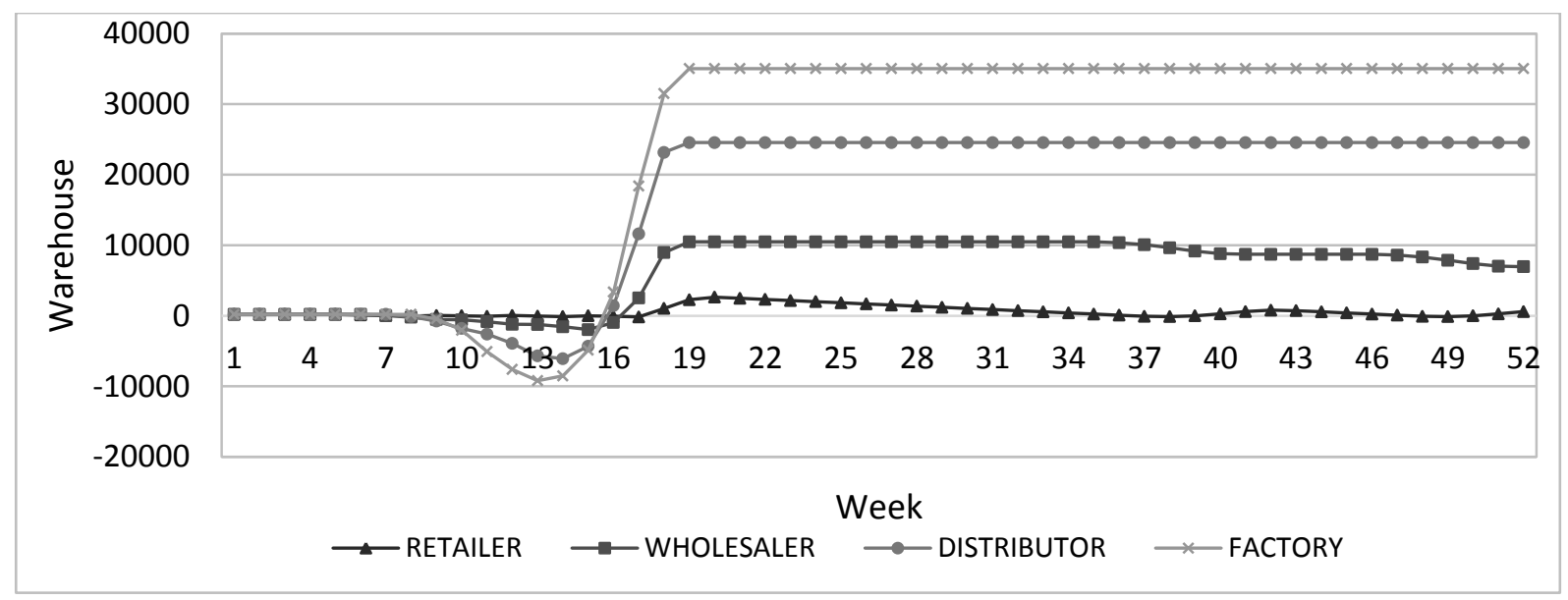

Figure 4: Stock levels of supply chain participants for case study 1 and stock keeping policy behaviour.

To avoid the bullwhip effects, numerous of different stock keeping policies are presented by listed literature. The most of researches from literature compared different solutions for one particular case study. In this paper, in order to reduce bullwhip effect, the mathematical model for order quantities is proposed for all three examined case studies. Preliminary experiments showed that functions other than linear showed better reactions to demand quantity change in some cases, but they are sensitive to successive changes of demand quantity, thus even increasing the bullwhip effect. In linear regression, the dependent variable $y$ is a linear combination of the parameters, and linear independent variables. For this purpose, 
three independent variables, $x_{1}, x_{2}$ and $x_{3}$ and four parameters, $a_{0}, a_{1}, a_{2}$ and $a_{3}$ are used for modelling. The order quantity of every participant in the supply chain can be expressed as $y$ in Eq. (1):

$$
y=a_{0}+a_{1} x_{1}+a_{2} x_{2}+a_{3} x_{3}
$$

The parameter $a_{0}$ is demand quantity received for the current period. The variable $x_{1}$ is the difference between current stock level and safety stock level. The variable $x_{2}$ is the difference between the current demand quantity and the demand quantity received in a previous period. The variable $x_{3}$ is a difference between the current demand quantity and average demand quantity in five previous periods. This problem represents multi-criteria optimization process. There are a number of different suboptimal solutions which are acceptable to supply chain participants according to their preferences. Overall goal $Q_{i}$, for $i^{\text {th }}$ case study, is response value which has to be minimized during optimization process by alternating parameters $a_{1}, a_{2}$ and $a_{3}$ (Eq. 2):

where:

$$
Q_{i}=w_{1} q_{1}+w_{2} q_{2}+w_{3} q_{3}+w_{4} q_{4}
$$

$w_{1}, w_{2}, w_{3}$ and $w_{4}$ - weight factors that form participants' preferences,

$q_{1}$ - sum of stock and backlog keeping costs; stock level cost is $1 € /$ week per item, while backlog cost is $2 € /$ week per item,

$q_{2}$ - total number of weeks with backlog, summed for all participants,

$q_{3}$ - mean absolute difference between stock level and safety stock for all participants,

$q_{4}$ - bullwhip effect measure according to Buchmeister et al. [25], which is the ratio between standard deviation of demands and standard deviation of orders.

For this paper purposes, values for $w_{1}, w_{2}, w_{3}$ and $w_{4}$ are taken $10^{-4}, 10^{-1}, 10^{-1}$ and 1 respectively. Those values can be adjusted according to participants' preferences. For instance, if participants want to achieve a lower $q_{1}$ goal, weight factor $w_{1}$ has to be increased in relation to other weight factors.

Examined optimal mathematical model which resulted with $Q_{1}=32.97$ is presented by Eq. (3):

$$
y=a_{0}+0.06 x_{1}+0.61 x_{2}+0.04 x_{3}
$$

The data about a sequence of released customer demands, the order quantities along the supply chain and the contents of all participants' stocks including backlogs are shown in Figs. 5 and 6.

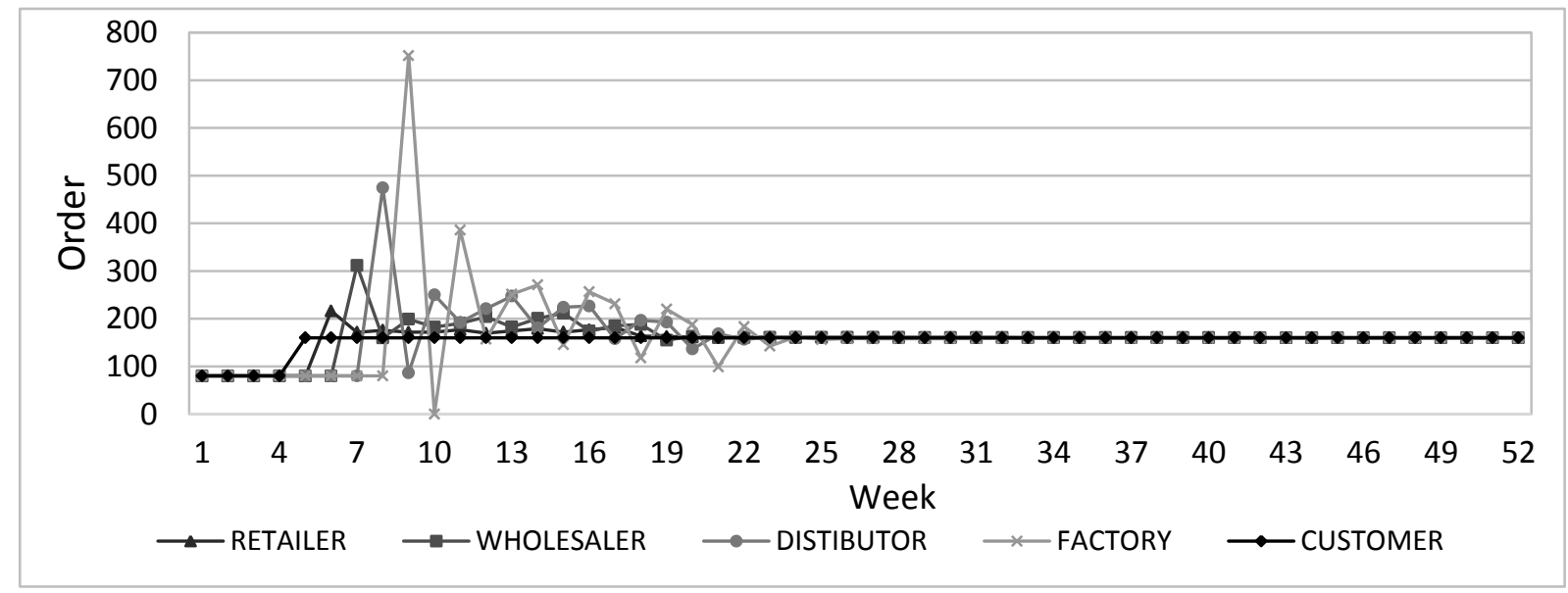

Figure 5: Customer demand and optimal order quantities of supply chain participants for case study 1. 


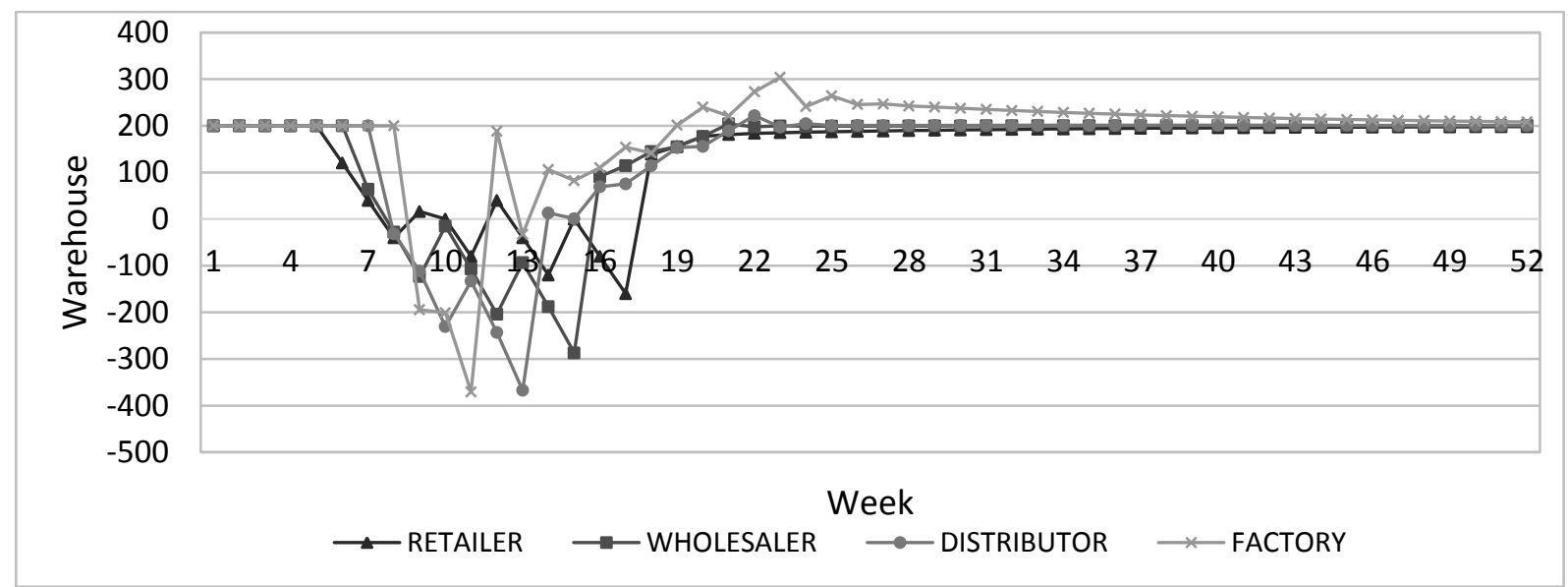

Figure 6: Stock levels according to the optimal mathematical model for case study 1.

Prior to optimization, by preliminary experiments, research solution field from value 0 to 1 is defined for $a_{1}, a_{2}$ and $a_{3}$. In the first iteration, whole research solution field in 0.1 increments of all investigated factors was performed to find global minimum with maximum reliability. Visual Basic for Applications tool embedded in Excel spreadsheet software was used. The second iteration of optimization examined research field in surrounding area of the optimal results, gained in the first iteration, in increments of 0.01 .

\subsection{Alternating and continuously increasing demand - case study 2}

Case study 2 used alternating and continuously increasing demand, inspired by Veza et al. [26]. For this particular demand sequence, optimal parameters are shown in Eq. (4), so the optimal mathematical model which resulted with $Q_{2}=24.7$ is:

$$
y=a_{0}+0.07 x_{1}+0.32 x_{2}+0.64 x_{3}
$$

The data about a sequence of released customer demand, the order quantities along the supply chain and the contents of every participant stocks including backlogs are shown separately for every participant of a supply chain in Figs. 7 and 8.

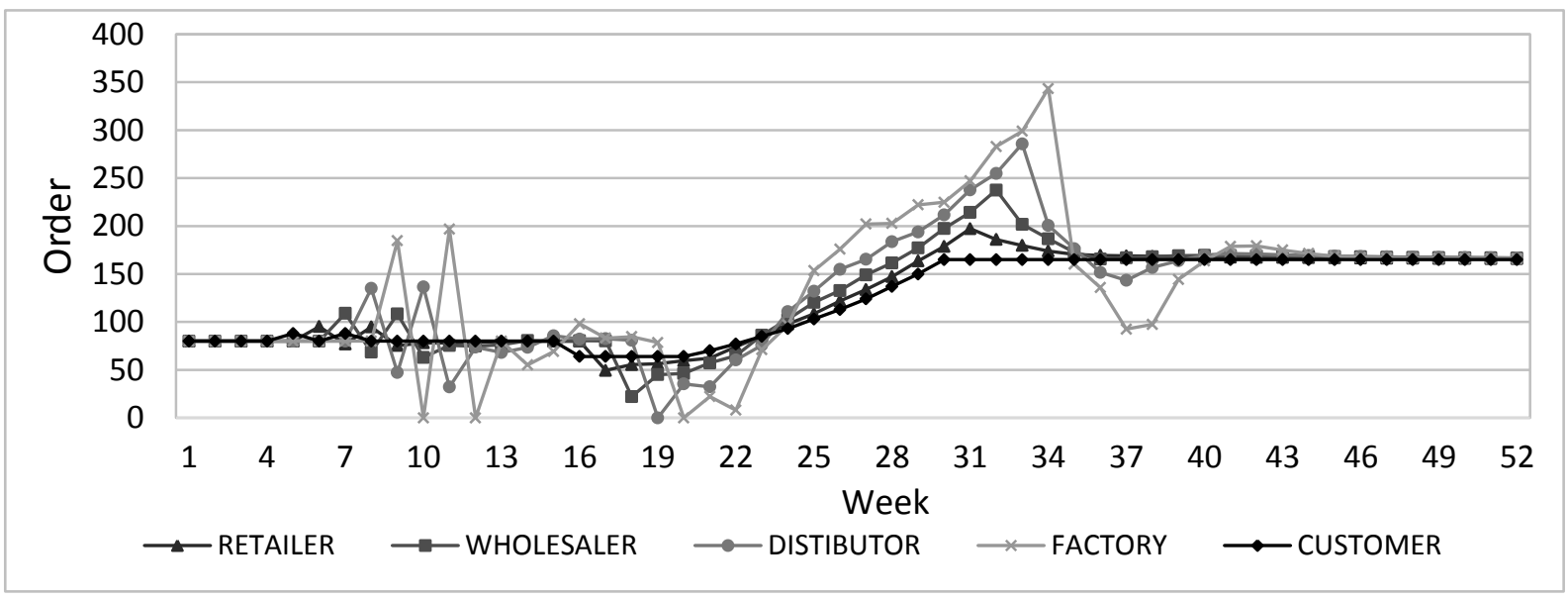

Figure 7: Customer demand and optimal order quantities of supply chain participants for case study 2. 


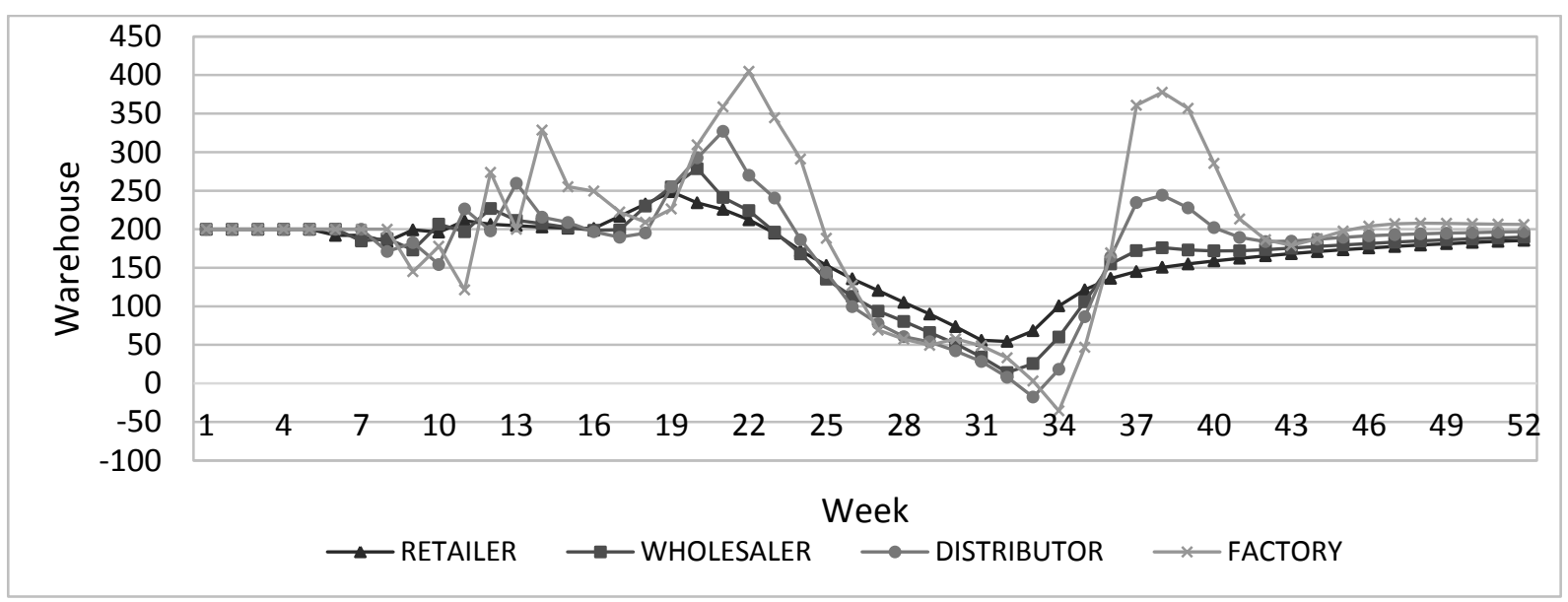

Figure 8: Stock levels according to the optimal mathematical model for case study 2.

The customer demands quantities are shown in Fig 7 and changes as follows:

- The customer demand is constant at the initial value of 80 items, up to period 4 .

- In the $5^{\text {th }}$ period the customer demand is increased by $10 \%$ and then decreased back to initial value immediately in the following period.

- Another increase of $10 \%$ is set in the $7^{\text {th }}$ period, followed by the decrease to initial demand.

- Periods 8 to 15 are set at the constant initial value to stabilize supply chain behaviour.

- In periods 16 to 21 constant demand of 64 items is set, as $80 \%$ of initial value.

- In the next periods, for every successive period, the demand is increased for approx. $10 \%$ up to 165 items. The level of 165 items per period is maintained to the end of the simulation.

\subsection{Real market demand - case study 3}

The real market demand is based on the case study presented by Buchmeister et al. [25]. Available data are extended to fit 52 periods of simulation runtime. The demands quantity changes are not deseasonalized [25]. Minimal demand is 26 items, and maximal demand is 179. For this case study optimal mathematical model which resulted with $Q_{3}=49.53$ is (Eq. $5)$ :

$$
y=a_{0}+0.39 x_{2}
$$

Variable $x_{3}$ is not taken into consideration at all. Trials that use two to five periods of previous customer demands for $a_{33}$ did not make any reduction of the overall goal. It even became higher, because reaction on the customer's demand change became slower. It means that knowing average demand in a previous period only disrupts the model, which was not a case in the previous case studies. The data about the sequence of released customer demand, the order quantities along the supply chain and the contents of every participant stocks including backlogs are shown separately for each participant of a supply chain in Figs. 9 and 10 . 


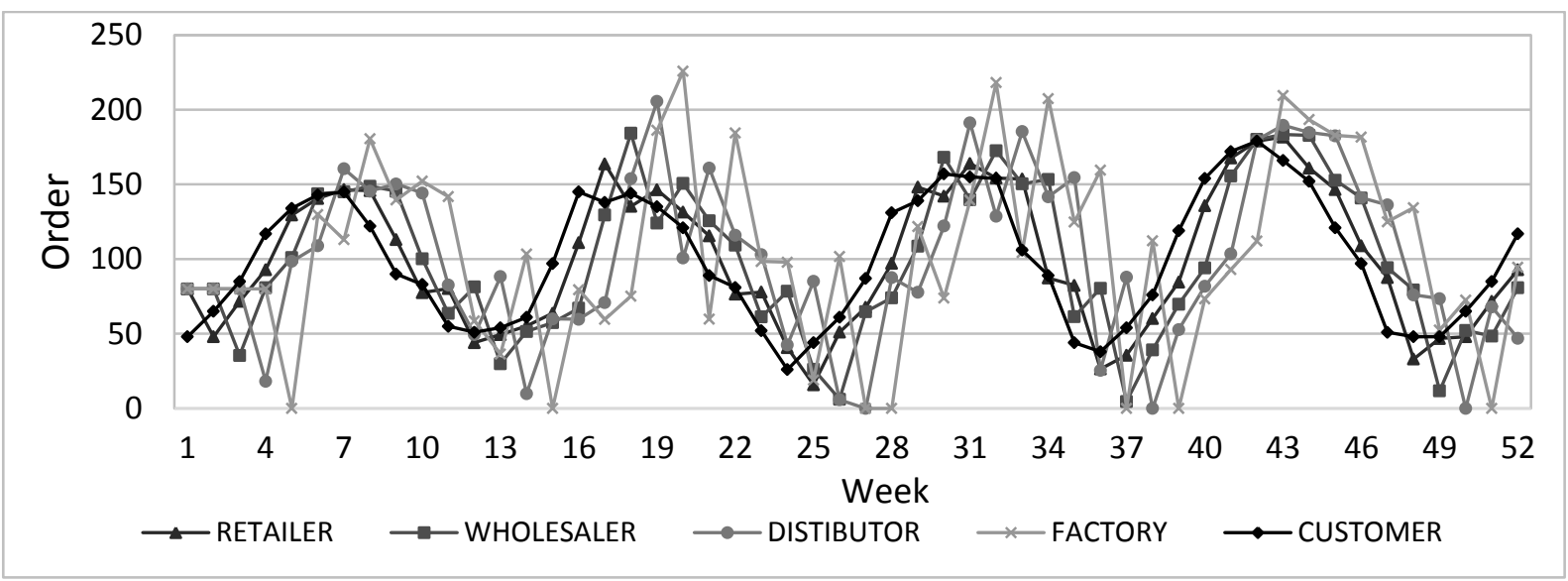

Figure 9: Customer demand and optimal order quantities of supply chain participants for case study 3.

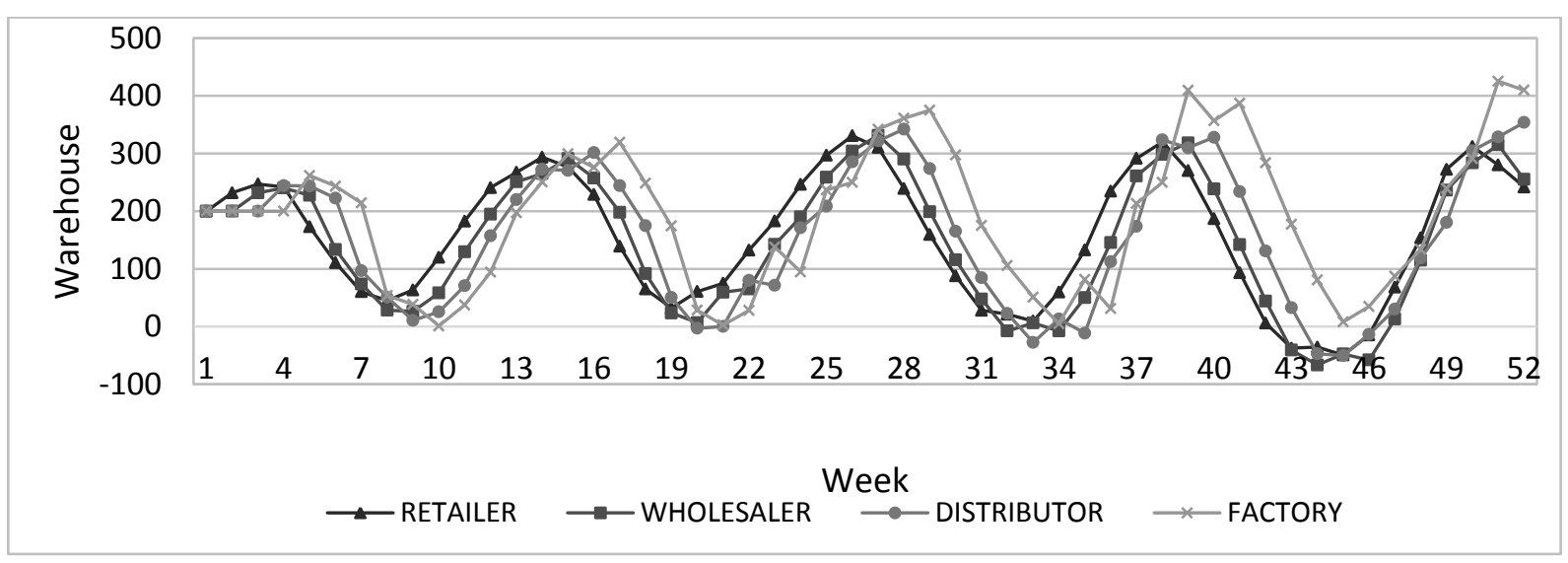

Figure 10: Stock levels according to the optimal mathematical model for case study 3.

\subsection{Common optimal mathematical model for all three case studies}

Upon determination of the optimal mathematical models for different case studies, the conclusion can be made. While the case studies 1 and 2 are taking into consideration all input variables $\left(x_{1}, x_{2}\right.$, and $\left.x_{3}\right)$, real market case study (case study 3 ) uses the only $x_{2}$. Elimination of the $x_{1}$ and the $x_{3}$ variables are caused by a significant change of customer demand, with the sinusoid pattern, which could be the case of demands for products that usually vary according to the seasons of year. But, in the industrial environment, the season changes are not so significant, compared to changes by other reasons related to the current economy situation, price fluctuations, competitors and a current position of the product in general product lifecycle curve.

In order to define common optimal mathematical model suitable for all three case studies, parallel optimization of the all three case studies are done. During the optimization process, total overall goal $Q_{t}$ presented by Eq. (6), is the response value which has to be minimized:

$$
Q_{t}=\sum_{i=1}^{3} Q_{i}
$$

For the all three case studies, optimal mathematical model is shown by Eq. (7). It resulted with total overall goal $Q_{t}=133.72$, while $Q_{1}=33.28, Q_{2}=35.66$ and $Q_{3}=64.78$ are shares of the total overall goals for case studies 1,2 and 3 respectively.

$$
y=a_{0}+0.06 x_{1}+0.59 x_{2}
$$


In Table I, comparison of the individual optimal models' responses and the common optimal model responses for the all three case studies is shown. Using the common model for participants' demands quantity results with response loss in comparison to using individual models for the all three case studies. Total loss of 26.52 is the lowest loss achievable, achieved by using the common optimal model instead of the individual optimal models.

Table I: Comparison of the individual model's and the common model responses.

\begin{tabular}{|c|c|c|c|c|c|c|c|c|c|}
\hline \multirow{2}{*}{ Case study } & \multicolumn{4}{|c|}{ Individual optimal mathematical models } & \multicolumn{4}{|c|}{ Common optimal mathematical model } & \multirow{2}{*}{ Loss } \\
\hline & $x_{1}$ & $x_{2}$ & $x_{3}$ & $Q_{i}$ & $x_{1}$ & $x_{2}$ & $x_{3}$ & $Q_{i}$ & \\
\hline Case study 1 & 0.06 & 0.61 & 0.04 & 32.97 & 0.06 & 0.59 & 0 & 33.28 & 0.31 \\
\hline Case study 2 & 0.07 & 0.32 & 0.64 & 24.7 & 0.06 & 0.59 & 0 & 35.66 & 10.96 \\
\hline Case study 3 & 0 & 0.39 & 0 & 49.53 & 0.06 & 0.59 & 0 & 64.78 & 15.25 \\
\hline$\sum$ & & & & 107.2 & & & & 133.72 & 26.52 \\
\hline
\end{tabular}

\section{CONCLUSION}

The concept of the Learning Factory offers an approach to meet the industries' requirements through simulation of a real business environment through specialized equipment. For the field of supply chain management, didactic simulator that uses electronic devices for participants' inputs, monitoring and calculation purposes, is developed. It is based on the traditional board Beer Game, which is able to present occurrence of the bullwhip effect in a supply chain. The bullwhip effect occurs in a case of the demand quantity change from achieved routine in a previous period. The second main prerequisite for bullwhip effect is a rapid response to the order quantity change with an intention for the resumption of stock level in one period according to the stock keeping policy. This results with amplified increase or decrease of the order quantity in the upstream supply chain stages.

The newly developed didactic tool presented in this paper reduces disadvantages of wellknown board Beer Game. Using the developed system, participants cannot see other participants' inventory level and order quantities, as they are positioned at four distanced tables. The whole communication goes through the system. There are no physical objects so all calculations and recordings on inventory or backlogs are done by the system, which is considerably faster. An additional advantage is ease of changing market demands scenarios, and by minor hardware and software changes, different types of serial and divergent Supply Chain Networks (SCN) could be simulated. Therefore, the new system is flexible in relation to traditional board Beer Game, it can simulate according to Bear Game scenario, but it can be easily reconfigured for simulation of other SCNs or problems in system dynamics field.

During the board Beer Game simulation, there is a fact that participant works as a team on reaching the same goal. They are siting close to each other which enables sharing of information to adjust order quantities that could lead to total avoidance of the bullwhip effect occurrence. Therefore, by further considerations in this paper, simulation and optimization of orders quantities along SCM is presented, in order to prove the fact that it is not possible to correctly predict customer demands and act properly upon those to prevent the bullwhip effect. For three significantly different case studies, using different customer scenario profiles, three individual optimal mathematical models were defined. As all three models differ from each other, one common mathematical model is subsequently defined, suitable for all three case studies with the best achievable summed response. The summed response to be minimized for the common optimal model was 133.72, compared with the sum of the individual optimal models' response which was 107.2. The increase of $24.7 \%$ is acceptable as this performance metric value and it is very sensitive to input parameters change. On the 
other side, defined mathematical model could be used effectively in any customer demand scenario case study.

In future work, noise factors like $O E E$, variable transportation lead times and warehouses capacity will be taken into consideration for integration into a newly developed system, and for modelling of similar mathematical models.

\section{ACKNOWLEDGEMENT}

This work has been fully supported by Croatian Science Foundation under the project Innovative Smart Enterprise - INSENT (1353).

\section{REFERENCES}

[1] Cachay, J.; Abele, E. (2012). Developing competencies for continuous improvement processes on the shop floor through learning factories - conceptual design and empirical validation, Procedia CIRP, Vol. 3, 638-643, doi:10.1016/j.procir.2012.07.109

[2] Gjeldum, N.; Mladineo, M.; Veza, I. (2016). Transfer of model of innovative smart factory to Croatian economy using Lean Learning Factory, Procedia CIRP, Vol. 54, 158-163, doi:10.1016/j.procir.2016.06.096

[3] Tisch, M.; Hertle, C.; Abele, E.; Metternich, J.; Tenberg, R. (2016). Learning factory design: a competency-oriented approach integrating three design levels, International Journal of Computer Integrated Manufacturing, Vol. 29, No. 12, 1355-1375, doi:10.1080/0951192X.2015.1033017

[4] Houlihan, J. B. (1985). International supply chain management, International Journal of Physical Distribution \& Materials Management, Vol. 15, No. 1, 22-38, doi:10.1108/eb014601

[5] Liang, Y.; Qiao, P. L.; Luo, Z. Y.; Song, L. L. (2016). Constrained stochastic joint replenishment problem with option contracts in spare parts remanufacturing supply chain, International Journal of Simulation Modelling, Vol. 15, No. 3, 553-565, doi:10.2507/IJSIMM15(3)CO13

[6] Cachon, G. P.; Fisher, M. (2000). Supply chain inventory management and the value of shared information, Management Science, Vol. 46, No. 8, 1032-1048, doi:10.1287/mnsc.46.8. $\underline{1032.12029}$

[7] Lee, H. L.; So, K. C.; Tang, C. S. (2000). The value of information sharing in a two-level supply chain, Management Science, Vol. 46, No. 5, 626-643, doi:10.1287/mnsc.46.5.626.12047

[8] Forrester, J. W. (1961). Industrial Dynamics, MIT Press, Cambridge, Massachusetts

[9] Dolgui, A.; Proth, J. M. (2010). Supply Chain Engineering, Springer, London

[10] Rother, M.; Shook, J. Y. (2003). Learning to See, The Lean Enterprise Institute, Cambridge

[11] Tempelmeier, H. (2006). Inventory Management in Supply Networks - Problems, Models, Solutions, Books-on-Demand, Norderstedt

[12] Lee, H. L.; Padmanabhan, V.; Whang, S. (1997). Information distortion in a supply chain: The bullwhip effect, Management Science, Vol. 43, No. 4, 546-558, doi:10.1287/mnsc.43.4.546

[13] Nishioka, Y. (2004). Collaborative agents for production planning and scheduling (CAPPS): a challenge to develop a new software system architecture for manufacturing management in Japan, International Journal of Production Research, Vol. 42, No. 17, 3355-3368, doi:10.1080/00207540410001695989

[14] Zhao, X.; Xie, J. (2002). Forecasting errors and the value of information sharing in a supply chain, International Journal of Production Research, Vol. 40, No. 2, 311-335, doi: $10.1080 / 00207540110079121$

[15] Simchi-Levi, D.; Kaminski, P.; Simchi-Levi, E. (2000). Designing and Managing the Supply Chain, McGraw-Hill Higher Education, New York

[16] Miragliotta, G. (2006). Layers and mechanisms: A new taxonomy for the bullwhip effect, International Journal of Production Economics, Vol. 104, No. 2, 365-381, doi:10.1016/ j.ijpe.2005.10.001

[17] Potter, A.; Disney, S. M. (2006). Bullwhip and batching: An exploration, International Journal of Production Economics, Vol. 104, No. 2, 408-418, doi:10.1016/j.ijpe.2004.10.018 
[18] Lee, H. L.; Padmanabhan, V.; Whang, S. (1997). The bullwhip effect in supply chains, MIT Sloan Management Review, Vol. 38, No. 3, 93-102

[19] Lummus, R. R.; Duclos, L. K.; Vokurka, R. J. (2003). The impact of marketing initiatives on the supply chain, Supply Chain Management: An International Journal, Vol. 8, No. 4, 317-323, doi:10.1108/13598540310490071

[20] Sterman, J. D. (1989). Modeling managerial behavior: misperceptions of feedback in a dynamic decision making experiment, Management Science, Vol. 35, No. 3, 321-339, doi:10.1287/ $\underline{\text { mnsc. 35.3.321 }}$

[21] Sterman, J. D. (1992). Teaching takes off: Flight simulators for management education, The Beer Game, OR/MS Today, No. 10, 40-44

[22] Buchmeister, B.; Friscic, D.; Palcic, I. (2013). Impact of demand changes and supply chain's level constraints on bullwhip effect, Advances in Production Engineering \& Management, Vol. 8, No. 4, 199-208, doi:10.14743/apem2013.4.167

[23] Cannella, S.; Dominguez, R.; Framinan, J. M. (2016). Turbulence in market demand on supply chain networks, International Journal of Simulation Modelling, Vol. 15, No. 3, 450-459, doi:10.2507/IJSIMM15(3)5.346

[24] Buchmeister, B. (2008). Investigation of the bullwhip effect using spreadsheet simulation, International Journal of Simulation Modelling, Vol. 7, No. 1, 29-41, doi:10.2507/ IJSIMM07(1)3.093

[25] Buchmeister, B.; Friscic, D.; Lalic, B.; Palcic, I. (2012). Analysis of the three-stage supply chain with level constraints, International Journal of Simulation Modelling, Vol. 11, No. 4, 196-210, doi:10.2507/IJSIMM11(4)3.212

[26] Veza, I.; Gjeldum, N.; Bilic, B.; Bajic, D. (2008). Reduction of oscillating demand magnification effect in supply chain, Proceedings of the $19^{\text {th }}$ International DAAAM Symposium, 1471-1472 